\title{
Kelola Kubikal Data Transaksional Sistem Informasi Rumah Sakit Dengan Teknik Online Analytical Processing
}

\author{
Feri Sulianta ${ }^{1}$, Raina Clarissa Philothra $\mathbf{R}^{1}$ \\ ${ }^{1}$ Universitas Widyatama Jl.Cikutra No. 204A \\ Email: feri.sulianta@widyatama.ac.id
}

\begin{abstract}
ABSTRAK
Data transaksional rumah sakit dapat diberdayakan lebih lanjut untuk ragam keperluan dan bukan hanya sebagai arsip riwayat pasien perseorangan saja. Berbagai informasi berharga dapat diungkapkan dari data transkasional rumah sakit yang dihasilkan dari sistem rekam medis.Dalam kasus ini untuk mendapatkan kejelasan yang melibatkan informasi menyeluruh yang juga melibatkan ragam sudut pandang dapat disolusikan dengan teknik Online Analytical Processing (OLAP). Teknik ini mampu mengakomodasi kelengkapan data yang nantinya menjadi framework untuk dianalisa secara seksama Mengacu pada data rekam medis dimana setiap pasien memiliki banyak keluhan dan latar belakang yang berbeda yang terelasi dengan sang pasien. Teknik OLAP mampu menyajikan data dalam bentuk multidimensi. Selanjutnya, OLAP akan melakukan eksekusi data yakni slicing(irisan) dan dicing(rotasi) yakni meringkas dan mengumpulkan sejumlah besar data, melakukan filtering, pengurutan, dan memberikan peringkat (rangking) yang akan memperkaya temuan berharga dari data kubikal.
\end{abstract}

Kata kunci: online analytical processing (olap), data rekam media, data kubikal, slicing, dicing.

ABSTRACT
Hospital transactional data can be further empowered for diverse purposes and not just as an individual patient history archive only. Various valuable information may be disclosed from transactional the data which is generated from the system. To clarify that involve thorough information that also involves diverse viewpoints are treated with techniques Online Analytical Processing (OLAP). This technique is able to accommodate the completeness of the data that will be analyzed carefully. Mengacu framework for the medical records where each patient has a lot of complaints and different backgrounds who terelasi with the patient. OLAP techniques capable of presenting data in a multidimensional form. Furthermore, OLAP will execute the data that is slicing (slice) and dicing (rotation) that summarize and collect large amounts of data, perform filtering, sorting, and rank (rank) that will enrich the valuable findings from the data cubes. Hospital transactional data can be further empowered for various purposes, and not just as an individual patient history archive only. Various valuable information may be disclosed from the hospital transkasional the data generated from the medical record system. To obtain complete clarity that also involves a variety of viewpoints are treated with techniques Online Analytical Processing (OLAP). This technique is able to accommodate the completeness of the data that will be the framework to be analyzed carefully. Referring to the medical records where each patient has a lot of complaints and different backgrounds related to the patient. OLAP techniques capable of presenting data in a multidimensional form. Furthermore, OLAP will execute the data that is slicing (slice) and dicing (rotation) that summarize and collect large amounts of data, perform filtering, sorting, and rank (rank) that will enrich the valuable findings from the data cubes.

Keywords: online analytical processing (olap), medical record data, data cubicles, slicing, dicing. 


\section{LATAR BELAKANG}

Salah satu rumah sakit swasta di bandung memiliki data pasien rawat inap dalam sistem sistem rekam medis. Data transaksional tersebut akan dianalisa guna menyingkapkan informasi yang berharga untuk membangun strategi bisnis, memberikan layanan dan dasar pembuatan kebijakan rumah sakit. Beberapa hal dari informasi yang dapat dieksplorasi, misalnya dengan dunia yang semakin berkembang dan penyakit pun beragam, pihak rumah sakit harus sigap mengantisipasi keluhan para pasien. Dalam hal ini teknik Online Analytical Processing akan diterapkan guna menskemakan basis data, analisa datadan menyingkapkan temuan berrharga. Secara prkatikal, teknik Online Analytical Processing pun dapat menghadirkan kebutuhan retrieval data diagnosa Langkah ini diharapkan mampu mengungkap banyak informasi yang sebelumnya tidak teralamati jika hanya mengandalkan sistem rekam medis dengan fitur sistem pemrosesan transaksi saja.

\section{METODOLOGI PENELITIAN}

OLAP atau disebut dengan Online Analytical Processing, merupakan metode menganalisa data (atau kumpulan data) secara interaktif tanpa harus menggunakan teknik pemrograman rumit. Pemakai cukup mengakses fitur grafis yang tersedia dalam OLAP. Analisa data menjadi mudah, pemakai dapat dengan mudah mengubah dan memposisikan data dengan fitur grafis yang interaktif. OLAP pada umumnya digunakan pada pembuatan laporan bisnis seperti laporan keuangan, penjualan, pemasaran, meramal data, analisa budget, business process management, dan meluas pada keperluan riset dan industri.

OLAP memampukan sistem analis menganalisa berbagai data dengan atribut beragam, misalnya saja data pasien berdasarkan penyakit yang diderita, waktu registrasi pasien, jenis asuransi yang digunakan, biaya pengobatan kemudian membandingkannya dengan data yang tersedia. Temuan seperti waktu puncak registrasi dan jenis pernyakit yang diderita atau dikeluhkan, jenis obat yang digunakan, atau bahkan jenis asurasi yang digunakan dapat menjadi dasar dalam membuat layanan lebih baik. Misalnya menyiapkan personel tambahan dalam waktuu-waktu tertentu yang didapati terjadinya puncak registrasi pasien, atau bahkan untuk strategi bisnis dengan menggandeng pihak asurasi guna memberikan tawaran produk asurasi lebih tepat sasaran.

Akan diperlihatkan secara mendasar komponen diperlukan dalam menjalankan $O L A P$ dan implementasi langkah-langkahnya sbb:

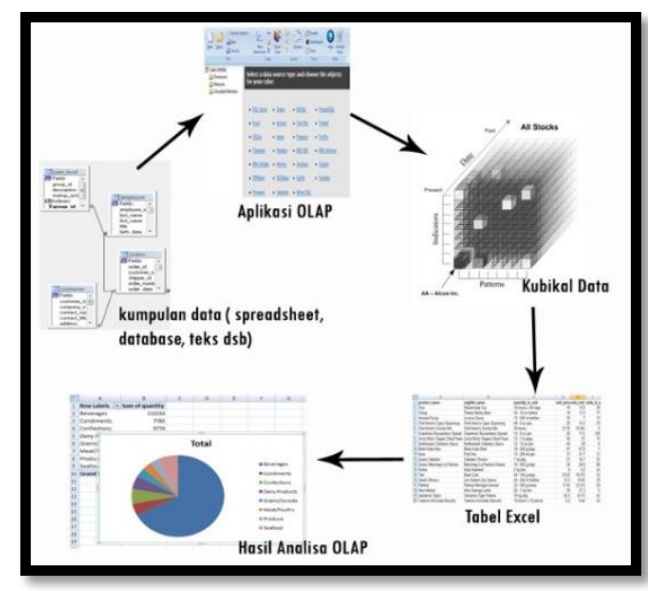

Gambar 1. Siklus pengolahan data dengan OLAP dan pemetaan ke dalam data kubikal

(Sumber : Feri Sulianta. OLAP Excel - Cara Hebat Excel Mengelola Data. Elexmedia Komputindo. Jakarta. 2011) 
Berbeda dengan sekedar tabel tunggal sederhana, diperlukan komponen lain untuk membangun $O L A P$, antara lain :

- Kumpulan tabel (tabel: kumpulan dari baris dan kolom).

- Relasi: keterhubungan antara satu tabel dengan tabel lain.

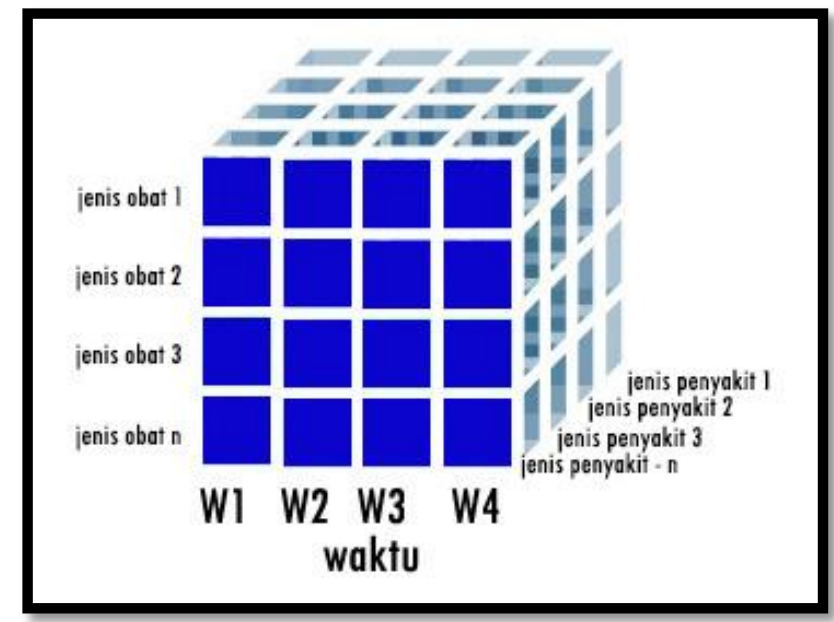

Gambar 2. Representasi kubikal data tiga dimensi

(Sumber : Feri Sulianta. OLAP Excel - Cara Hebat Excel

Mengelola Data. Elexmedia Komputindo. Jakarta. 2011)

Untuk membentuk data multi dimensi dibutuhkan banyak tabel yang terelasi satu sama lain, hal ini penting dalam membangun kelengkapan informasi. Selain membutuhkan data-data yang bergantung pada tabel-tabel lain, data multi dimensi memiliki atribut tersendiri untuk bisa dikelola dalam OLAP. Tiga atribut ini yaitu:

- Dimensi (dimension): atribut yang ditinjau.

- Pengukur (measurement): besaran yang dapat diukur mengacu pada irisan antara dimensi yang ditinjau.

- Kalkulasi (hasil pengukuran): hasil pengukuran suatu irisan (measurement).

Dengan membangun OLAP maka data yang diorganisasi dalam tabel dapat diberdayakan lagi untuk keperluan analisa. Informasi yang bernilai tidak ditemukan jika mengandalkan tabel tunggal yang hanya mengorganisasi baris dan kolom saja. Setelah mendapati wujud dari data transaksional. Selanjutnya data mentah harus diorganisasi terlebih dahulu dalam tabel -tabel. Selanjutnya relasi dibuat untuk membangun keterikatan antara satu tabel dengan tabel lainya.

Filtering merupakan hasil pada data OLAP yang akan meringkas dan mengumpulkan sejumlah besar data, melakukan filtering, pengurutan,dan memberikan peringkat (rangking), membandingkan beberapa set dari data, Membuat sketsa/bagan/diagram, menganalisis dan menemukan pola dari data, dan menganalisis kecenderungan data.Untuk mendapatkan pengetahuan demikian, maka cara yang ditempuh untuk menyingkapkan temuan berharga dari data tersebut yakni menggunakan data OLAP dengan filtering.OLAP mampu memetakan data dalam bentuk dimensioal cube (dimensi kubikal), kemudian masing-masing kubikal dapat dengan mudah dibandingkan, Pihak pengambil keputusan mudah dan cepat ketika mencari penyebab permasalahan yang dihadapi.

Perangkat lunak yang digunakan untuk mengimplementasikan data pasien rawat inap ini guna melakukan irisan dan rotasi data yang seketika mampu menghasilkan informasi yakni Olap Cube.Aplikasi ini akan membaca data yang disimpan dalam format $M s$. Access. Selanjutnya, melakukan seleksi dimension dan measures yang ingin diproses melalui Build Cube OLAP Cube. 
Konfigurasi komputer yang digunakan dalam penelitian yakni: Sistem Operasi Windows 8, Processor Intel Celeron Processor 1019\& $1 \mathrm{GHz}, 2 \mathrm{MB}$ L3 cache, dengan spesifikasi memori $4 G B D D R 3$. Dalam kasus ini, hanya sebagai data saja yang akan diambil dari basis data transaksional yang dipetakan dalam 1 tabel tunggal setelah proses denormalisasi dengan mengeksekusi perintah Structure Query Language (SQL).
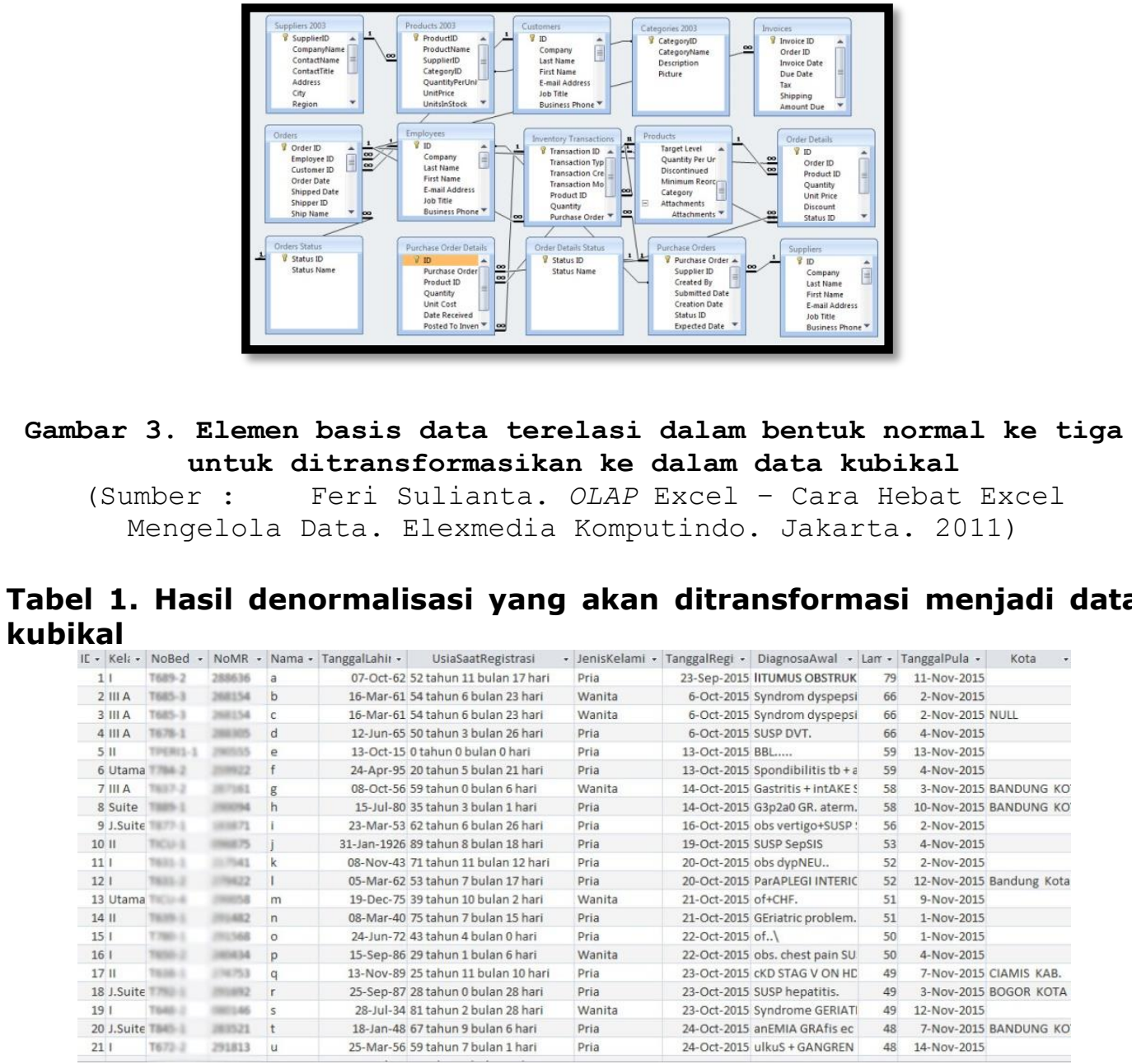

Data mentah tersebut mencitrakan data pasien rawat inap diambil dalam kurun waktu dua minggu dengan karakteristik yakni 16 atribut dan 953 record. Selanjutnya, menentukan row data yang diiris atau slicing dan menentukan sudut pandang yang ingin dilihat dari data atau dicing. Dikatakan sebelumnya data kubikal virtual dapat diubah sedemikan rupa untuk mencari temuan-temuan lain lagi yang berharga. Hal ini dilakukan menggunakan beberapa jenis metoda pengoperasian pada data kubikal virtual. Pada tahan inilah observasi data dilakukan yang mencakup:

- Membuat irisan/ Slicing.

- Membuat banyak irisan/Dicing. Drill Up.

- Drill Down.

- Rotasi atau Pivoting.

Berikut akan dijelaskan satu persatu untuk setiap operasi pada $O L A P$.

- Irisan ( OLAP slicing ) : Irisan atau slicing adalah mengambil atau mengiris satu dimensi dari data virtual kubikal untuk keperluan penyederhanaan informasi atau untuk membuang informasi yang tidak diperlukan dalam analisis. 
- Irisan Berganda (OLAP dicing): Irisan berganda atau dicing adalah irisan dilakukan lebih dari dua dimensi data. Dimensi batasan waktu dan area tidak berubah, tetapi tiga kategori suatu item diambil untuk analisa lebih lanjut.

- OLAP Drill-up dan Drill Down : Drill Down dan Drill Up merupakan teknik analisa untuk menspesifikasi atau mengeneralisasi informasi. Semakin ke atas $(U P)$ maka informasi yang didapat semakin ringkas dan semakin ke bawah (Down) maka informasi yang didapat semakin rinci. Kubikal virtual (kiri) jika ditranslasikan ke kubikal (kanan) disebut Drill Down sebaiknya dari kanan ke kiri disebut dengan Drill UP.Drill Down dilihat sewaktu area kubikal yang dikategorikan dalam produk layanan seperti misalnya ruang pasien kelas $\mathrm{A}$, ruang pasien kelas $\mathrm{B}$, ruang pasien kelas $\mathrm{C}$ atau ruang pasien VIP.

- Rotasi atau OLAP pivoting: Rotasi atau Pivoting dilakukan dengan memutar atau merotasi data kubikal virtual untuk mendapatkan sudut pandang berbeda terhadap data yang dianalisa. Rotasi data kubikal virtual sedemikian rupa, akan mengubah fokus analisa, misalnya analisa berbasiskan jenis penyakit menjadi berbasis kurun waktu.

Temuan informasi baru bisa muncul seperti degradasi penggunaan layanan asuransi tertentu setiap tahunnya. Sebelum dirotasi hal ini tidak nampak karena jumlah pasien masih memiliki tingkat loyalitas tinggi pada rumah sakit yang bersangkutan.

Tahap-tahap menggunakan OLAP dalam menganalisa data relatif mudah, berikut langkahnya :

1. Mengkoneksikan OLAP ke sumber data atau data source yang akan dianalisa.

2. Menambahkan tabel yang diperlukan dari data source.

3. Membangun Relasi antar Tabel.

4. Lakukan drag dan drop mouse untuk field atau kolom pada tabel dalam menentukan 'dimension' dan 'measure'.

5. Membangun kubikal

Data apapun dapat digunakan asalkan memiliki ODBC Driver (middleware untuk basis data agar basis data dapat dikenali oleh sistem yang berbeda) yang cocok untuk database tersebut maka OLAP dapat mengenali datanya. Atribut memaksudkan jumlah kolom keterangan pasien rawat inap sedangkan record memaksudkan jumlah pasien rawat inap yang terjadi selama kurun waktu dua minggu. Agar data dapat diidentifikasi untuk dilakukan pengirisan berbasis atribut menggunakan Olap Cube, maka data pada tabel tunggal tersebut harus diintegrasikann pada apliaksi OLAP sepenuhnya. Sehingga didapati transformasi data pasien rawat inap sebagai berikut:

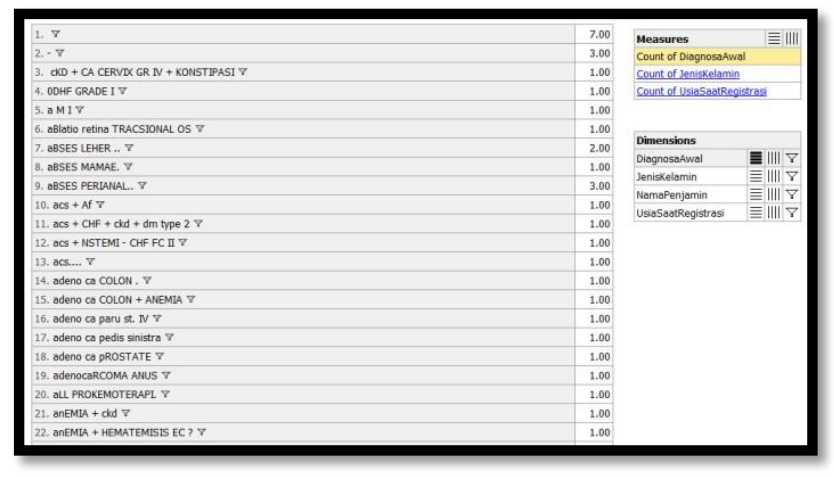

\section{Gambar 4. Menentukan irisan pada atribut dan data row untuk membangun temuan}

Hingga tahap ini, data mentah sudah terorganisasi kedalam filter yang adalah pengetahuan hasil dari kelola dan drilling data kubikal. 


\section{ANALISIS DAN PEMBAHASAN}

Hasil data mentah yang terfilter dipresentasikan dalam diagram lingkaran yang secara visual menjelaskan dimension dan measures.

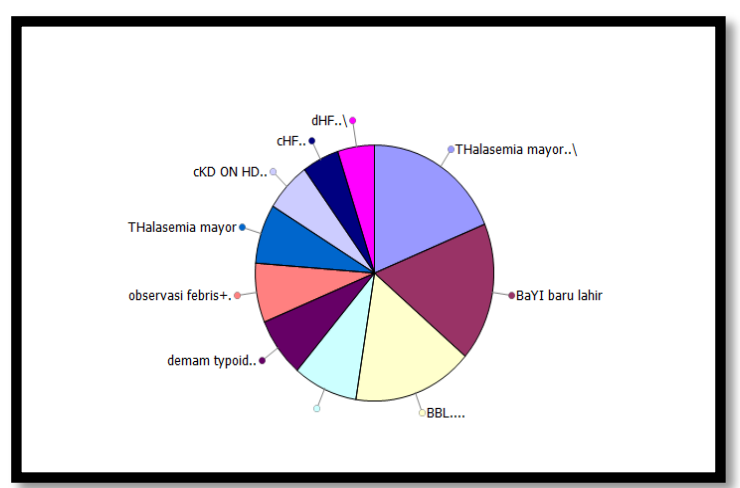

Gambar 5.Top 10 Diagnosa Awal

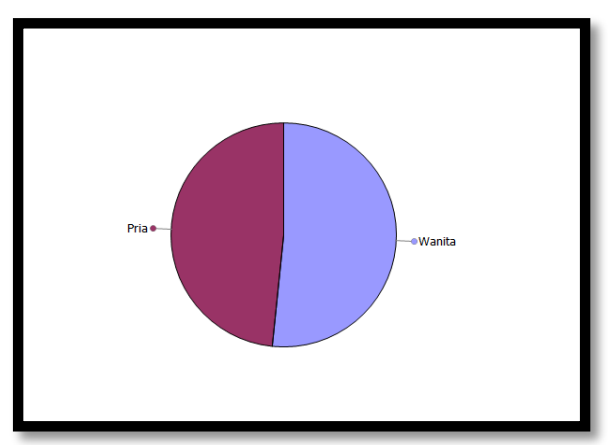

Gambar 6.Top 10 Jenis Kelamin

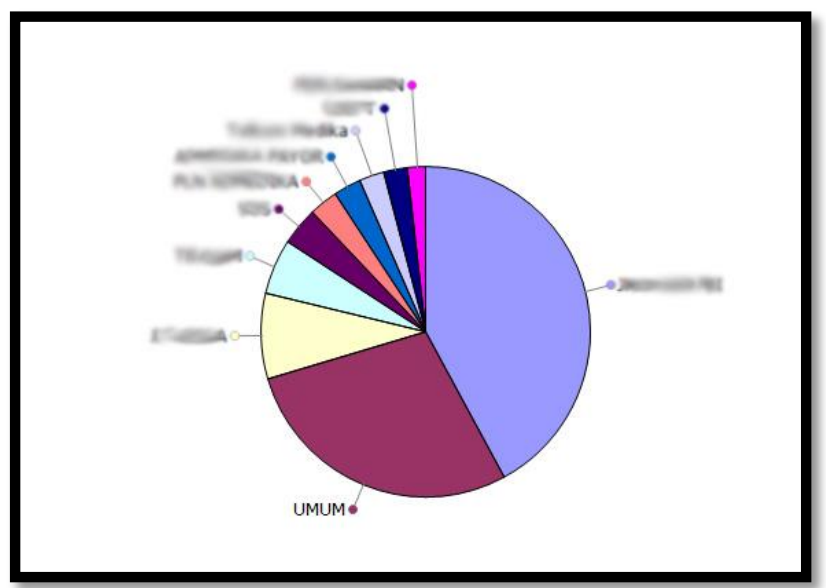

Gambar 7.Top 10 Nama Penjamin Pasien (data konfidensial tidak diperlihatkan) 


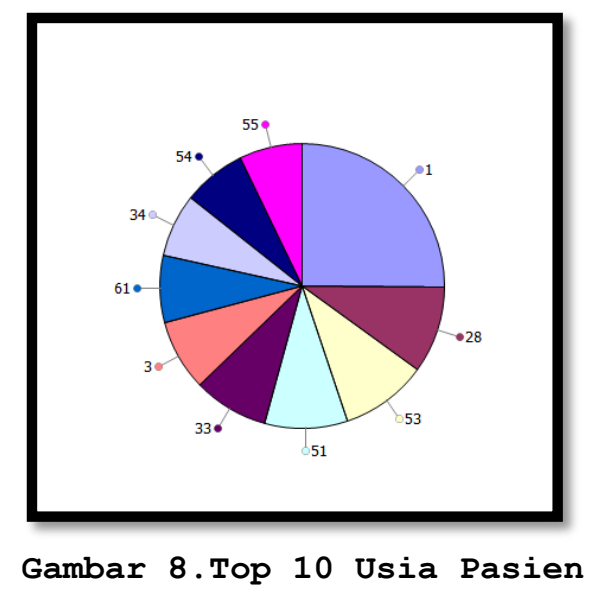

Pengetahuan yang terungkap yang sekaligus dapat dijadikan basis untuk mengetahui hasil banyaknya kasus dua minggu rawat inap pasien yakni:

- Gambar 5: memperlihatkan hasil diagnosa dari data rawat inap pasien yang menunjukan banyak kasusnya adalah Thalasemia major.

- Gambar 6: memperlihatkan hasil jenis kelamin yang memiliki banyak kasus adalah wanita.

- Gambar 7: memperlihatkan hasil penjamin pasien atau asuransi yang paling banyak digunakan oleh pasien yang dating berobat rawat inap adalah JKN Non PBI atau BPJS.

- Gambar 8: memperlihatkan hasil usia pasien yang banyak kasus yang pertama usia satu tahun merupakan bayi lahir dan selanjutnya usia dengan hasil yang sama adalah usia 28 dan 53 .

\section{KESIMPULAN}

Penalaran dengan OLAP memampukan sistem analis dalam membangun sistem analitik yang baik dan tepat sasaran sehubungan kondisi basis data yang dimiliki perusahaan. Sewaktu data yang diinginkan terbentuk dan hasil dinginkan terpenuhi, sebenarnya prototype (model) sudah terbentuk dan sudah siap dikomunikasikan dengan pihak manajemen rumah sakit. Dalam kasus ini, teknik OLAP mampu menyingkapkan informasi pada data pasien rawat inap, yakni berupa pie guna dijadikan acuan untuk rumah sakit. Rumah sakit dapat mengantisipasi untuk kesiapan menerima pasien karena sudah difiltering data menggunakan olap.Informasi temuan dari OLAP pada rumah sakit tertentu dapat ditindak lanjuti oleh pemerintah atau dinas kesehatan guna mengantisipasi termasuk

\section{DAFTAR RUJUKAN}

[1] A. Motro. Accommodating Imprecision in Database Systems: Issues and Solutions. SIGMOD Record, 19(4):69-74, 1990.

[2] A. Motro. Sources of Uncertainty, Imprecision and Inconsistency in Information Systems. In Uncertainty Management in Information Systems, pages 9-34. 1996.

[3] A. Shoshani. OLAP and Statistical Databases: Similarities and Differences. In PODS 1997.

[4] Bernardino J., et al. Approximate Query Answering Using Data Warehouse Striping. Journal of Intelligent. 2002

[5] Body M., et al. A Multidimensional and Multiversion Structure for OLAP Applications DOLAP'02, November 8, McLean, Virginia, USA. 2002.

[6] D T Pham, S S Dimov, and C D Nguyen. Selection of $K$ in $K$-means clusteringProc. IMechE Vol. 219 Part C: J. Mechanical Engineering Science, Cardiff University, Cardiff, UK. 2004. 
[7] D. Burdick, P. M. Deshpande, T. S. Jayram, R. Ramakrishnan, and S. Vaithyanathan. OLAP over uncertain and imprecise data. In VLDB 2005.

[8] H.-J. Lenz and B. Thalheim. OLAP Databases and Aggregation Functions. In SSDBM 2001.

[9] Rui Oliveira, Jorge Bernardino. Building olap tools over large databases. Isec Instituto Superior de Engenharia de Coimbra, Polytechnic Institute of Coimbra. Quinta da Nora, Rua Pedro Nunes, P-3030-199 Coimbra, Portugal.

[10] T. B. Pedersen, C. S. Jensen, and C. E. Dyreson. Supporting Imprecision in Multidimensional Databases Using Granularities. In SSDBM, 1999.

[11] T.Minka. Expectation-maximization as lower bound maximization.,1998.

[12] S. I. McClean, B. W. Scotney, and M. Shapcott. Aggregation of Imprecise and Uncertain Information in Databases. IEEE TKDE, 13(6):902-912, 2001.

[13] Feri Sulianta. OLAP Excel - Cara Hebat Excel Mengelola Data. Elexmedia Komputindo. Jakarta. 2011.

[14] Chaudruri. S., Dayal U. An Overview of Data Warehousing and OLAP technology. Sigmod Record. 1997.

[15] S. Abiteboul, R. Hull, and V. Vianu. Foundations of Databases. Addison-Wesley, 1995.

[16] Codd, E.F., et al. C.T.: Providing OLAP to User Analysts: an it Mandate. Technical Report, E.F. Codd \&Associates. 1993. 